\title{
UNILATERAL CONTACT, FRICTION AND ADHESION : 3D CRACKS IN COMPOSITE MATERIALS
}

\author{
Michel Raous \\ Laboratoire de Mécanique et d'Acoustique - CNRS \\ Marseille - France \\ Yann Monerie \\ Laboratoire de Mécanique et d'Acoustique - CNRS \\ Marseille - France
}

The model coupling adhesion, unilateral contact and friction, developed by M. Raous, L. Cangémi and M. Cocou, is extended here for studying propagating cracks in fiber-reinforced composites. The brittle fracture of the bulk materials (fiber and matrix) is described by a timeindependent version of the model. In this case, jumps in the evolution of the solution may occur and a dynamic formulation has to be used. This is performed by adapting a dynamic formulation due to J.J. Moreau and $\mathrm{M}$. Jean to this problem. Numerical simulations of 3D fracture of composite materials are then presented.

\section{Introduction}

The present work deals with interface problems where an initial adhesion due to chemical or thermal treatments can disappear during the loading and be replaced by frictional sliding. A model taking into account adhesion, friction and unilateral contact was proposed by M. Raous, L. Cangémi and M. Cocou (the RCC model) with a quasistatic formulation in Raous et al. $(1997,1999)$. It was used to simulate the micro-indentation of a fiber in a composite material. A comparison between this model and those developed by Tvergaard (1990), Allix et al. (1995, 1998), Ladevèze (1995), Michel and Suquet (1994), Michel et al. (1994) and Chaboche et al. $(1997,2001)$ was presented in Monerie et al. (1998). In the RCC model, using the adhesion intensity vari- 
able introduced by Frémond (1987, 1988) and Trong Dinh Tien (1990), adhesion, friction and unilateral contact are described via an unilateral elastic behaviour of the interface which fulfills the non penetration conditions and depends on the intensity of adhesion. Viscosity was taken into account in the evolution of the adhesion intensity.

In the present work, the model is extended and a new formulation is proposed in order to describe the propagation of a crack in a composite material and to study the interactions occurring between the crack and the fiber-matrix interfaces. To study the crack propagation, a model without interface viscosity has to be used (and friction will be neglected). In this case, rapid changes in the evolution of the solution may occur and a dynamic formulation has to be used. We present here :

- a new form of the RCC model introducing a new term which gives a better transition from adhesion to friction,

- a dynamic formulation, which is an extension to the RCC model of the Non Smooth Contact Dynamics method (NSCD method) developed by Jean (1999) and Moreau (1988, 1999),

- the simulation of 3D fracture in a composite material.

\section{The model coupling adhesion, friction and unilateral contact}

The model given by relations (1) to (3) differs from the standard RCC model (see Raous et al. (1999)) because of the term $(1-\beta)$ in the friction law. This means that friction is not active when adhesion is still complete and that the friction threshold progressively increases as the adhesion decreases. In this model :

- adhesion is characterized by the variable $\beta$ (see Frémond $(1987,1988)$ and Trong Dinh Tien (1990)), where $1 \geq \beta \geq 0$, and $\beta=1$ corresponds to total adhesion, and $\beta=0$ to no adhesion;

- unilateral stiffnesses $\beta^{2} C_{\mathrm{N}}$ (normal) and $\beta^{2} C_{\mathrm{T}}$ (tangential) of the interface, depending on the adhesion intensity, ensure a continuous behaviour during the competition between friction and adhesion;

- a viscosity $b$ is included in the evolution of the adhesion intensity $\beta$ (this viscosity is neglected for modeling crack propagation and the formulation and the numerical treatment will be adapted to this case in the following);

- in (3), the Laplacian term $k \Delta \beta$ introduces a non local adhesion, but it will not be taken into account here. 


\section{$2.1 \quad$ The model}

The behaviour of the interface is given by the following relations, where (1) characterizes the unilateral contact with adhesion, (2) the Coulomb friction with adhesion, and (3) the evolution of the adhesion intensity $\beta$.

$$
\begin{gathered}
-R_{\mathrm{N}}^{r}+\beta^{2} C_{\mathrm{N}} u_{\mathrm{N}} \geq 0, \quad u_{\mathrm{N}} \geq 0, \quad\left(-R_{\mathrm{N}}^{r}+\beta^{2} C_{\mathrm{N}} u_{\mathrm{N}}\right) \cdot u_{\mathrm{N}}=0 \\
R_{\mathrm{T}}^{r}=\beta^{2} C_{\mathrm{T}} u_{\mathrm{T}}, \quad R_{\mathrm{N}}^{r}=R_{\mathrm{N}} \\
\left\|R_{\mathrm{T}}-R_{\mathrm{T}}^{r}\right\| \leq \mu(1-\beta)\left|R_{\mathrm{N}}-\beta^{2} C_{\mathrm{N}} u_{\mathrm{N}}\right|
\end{gathered}
$$

with

$$
\begin{aligned}
& \text { if }\left\|R_{\mathrm{T}}-R_{\mathrm{T}}^{r}\right\|<\mu(1-\beta)\left|R_{\mathrm{N}}-\beta^{2} C_{\mathrm{N}} u_{\mathrm{N}}\right| \Rightarrow \dot{u}_{\mathrm{T}}=0, \\
& \text { if }\left\|R_{\mathrm{T}}-R_{\mathrm{T}}^{r}\right\|=\mu(1-\beta)\left|R_{\mathrm{N}}-\beta^{2} C_{\mathrm{N}} u_{\mathrm{N}}\right| \Rightarrow \exists \geq 0, \dot{u}_{\mathrm{T}}=\lambda\left(R_{\mathrm{T}}-R_{\mathrm{T}}^{r}\right), \\
& \dot{\beta}=-\left[\left(w-\beta\left(C_{\mathrm{N}} u_{\mathrm{N}}^{2}+C_{\mathrm{T}}\left\|u_{\mathrm{T}}\right\|^{2}\right)-k \Delta \beta\right)^{-} / b\right]^{1 / p} \text { if } \beta \in[0,1[, \\
& \dot{\beta} \leq-\left[\left(w-\beta\left(C_{\mathrm{N}} u_{\mathrm{N}}^{2}+C_{\mathrm{T}}\left\|u_{\mathrm{T}}\right\|^{2}\right)-k \Delta \beta\right)^{-} / b\right]^{1 / p} \text { if } \beta=1 .
\end{aligned}
$$

where $R_{\mathrm{N}}$ and $u_{\mathrm{N}}$ are the algebraic values of the normal components of the contact force and of the relative displacement between the two bodies (occupying the domains $\Omega^{1}$ and $\Omega^{2}$ ) defined on the contact boundary $\Gamma_{c}$, and $R_{\mathrm{T}}$ and $u_{\mathrm{T}}$ are the tangential components of this contact force and of this relative displacement. The constitutive parameters of this interface law are as follows :

- $C_{\mathrm{N}}$ and $C_{\mathrm{r}}$ are the initial stiffnesses of the interface (when adhesion is complete),

- $\mu$ is the friction coefficient,

$-w$ is the decohesion energy,

$-p$ is a power coefficient ( $p=1$ in what follows),

$-k=0$ in what follows.

Figure 1 gives the normal behaviour of the interface during loading and unloading (in Figure $1, u_{N}^{0}=\sqrt{\omega / C_{\mathrm{N}}}$ and $R_{N}^{0}=\sqrt{\omega C_{\mathrm{N}}}$ ). It should be noted that strict unilateral conditions are enforced (Signorini conditions), and that neither penalization nor compliance are used for the unilateral contact (no extra parameters are needed).

Figure 2 gives the tangential behaviour (in Figure 2, $u_{T}^{0}=\sqrt{\omega / C_{\mathrm{T}}}$ and $R_{T}^{0}=\sqrt{\omega C_{\mathrm{T}}}$ ). When the stresses and displacements are very small, the behaviour of the interface is elastic. When the local elastic energy reaches the threshold $w$ (decohesion energy), the intensity of adhesion 
begins to decrease, the apparent stiffnesses $\beta^{2} C_{\mathrm{N}}$ and $\beta^{2} C_{\mathrm{T}}$ also begin to decrease (softening) and the friction begins to act. When $\beta$ tends towards zero, classical Coulomb friction behaviour is obtained (the limit is asymptotic). This behaviour can be compared with that of the standard RCC model given in Figure 3, where the dotted line gives the evolution with infinitely small velocities. Figure 3 gives a clearer picture than Figure 2 of the energy exchanges. The interface energy is dissipated by viscosity, friction or adhesion (when the intensity of adhesion begins to decrease). A reversible elastic part is stored at the interface.

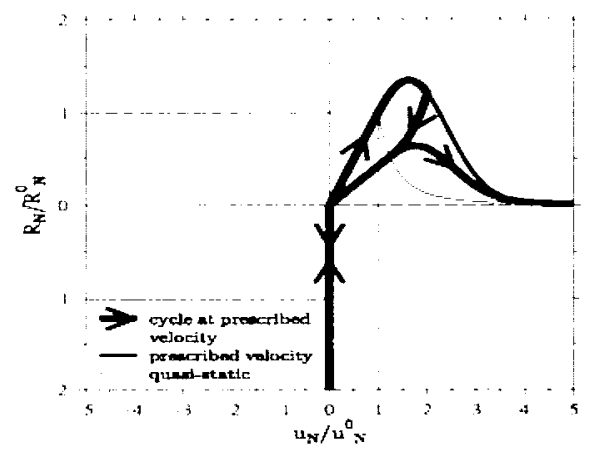

Figure 1. Normal behaviour of the interface.

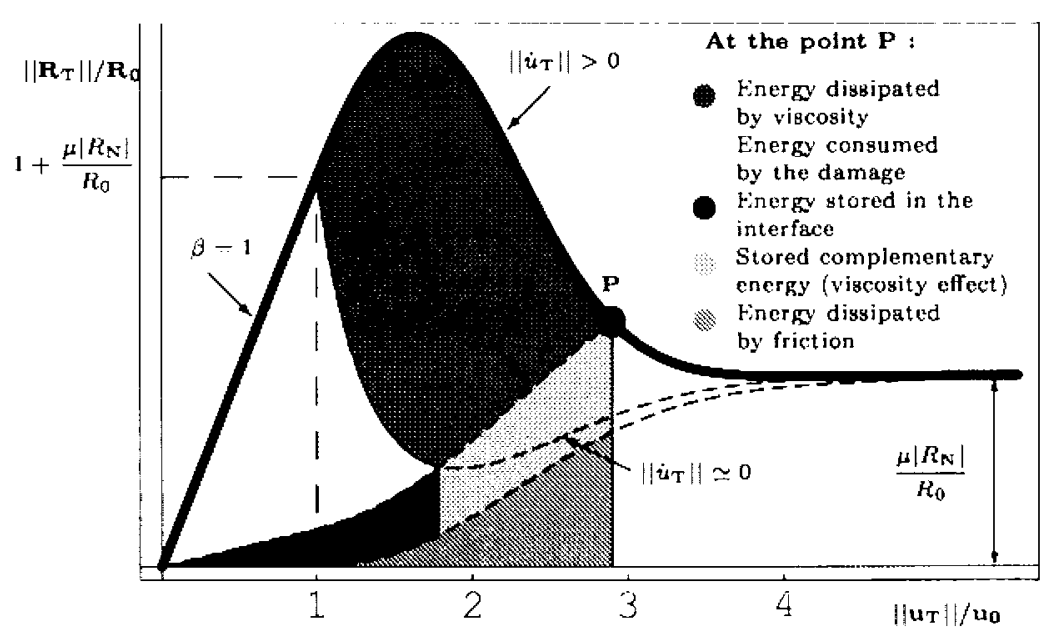

Figure 2. Tangential behaviour of the interface (present model). 


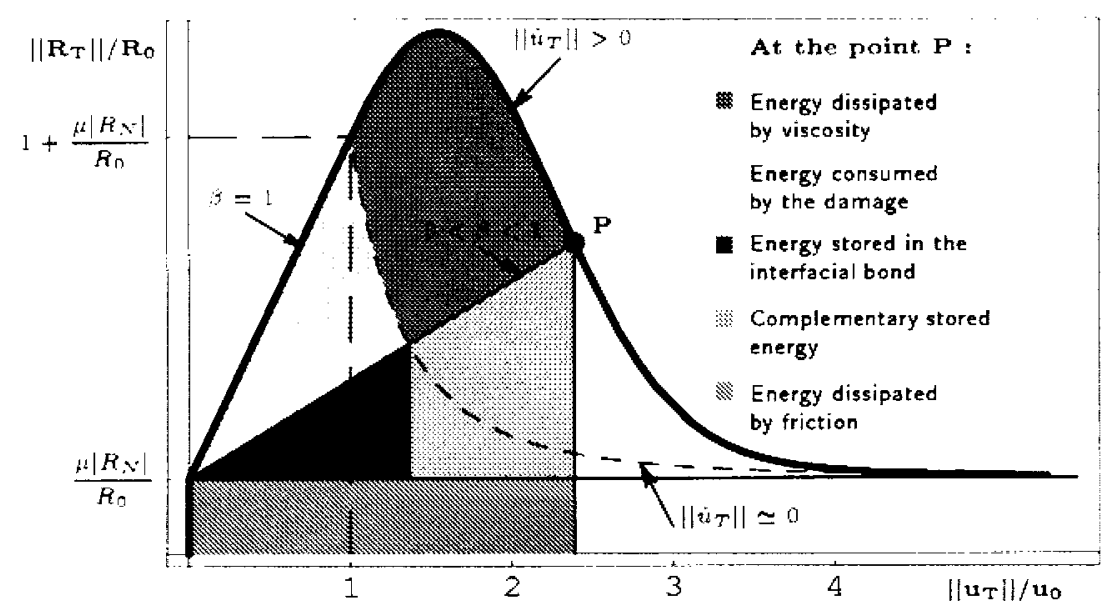

Figure 3. Tangential behaviour of the interface (RCC model).

\subsection{Thermodynamic basis}

The interface is considered as a material surface and the following thermodynamic variables are introduced : the relative displacements $\left(u_{\mathrm{N}} n, u_{\mathrm{T}}\right)$ and the adhesion intensity $\beta$ are chosen as the state variables, and the contact force $R$ and a decohesion force $G$, as the associated thermodynamic forces. The thermodynamic analysis given for the RCC model in Raous et al. (1999) can be extended to the present model in order to obtain the model given by relations (1) to (3). The following choices (4) and (5) are made for the free energy $\Psi\left(u_{\mathrm{N}}, u_{\mathrm{T}}, \beta\right)$ and the potential of dissipation $\Phi\left(\dot{u}_{\mathrm{T}}, \dot{\beta}\right)$ (in the case when $k=0$ ). Because of the lack of differentiability or convexity of some terms, the state laws and the complementary laws have to be expressed as differential inclusions (see Moreau (1988), Raous (1999)). In (4), the indicator function $I_{\tilde{K}}$ (where $\widetilde{K}=\{v / v \geq 0\}$ ) imposes the unilateral condition $u_{\mathrm{N}} \geq 0$ and the indicator function $I_{P}$ (where $P=\{\gamma / 0 \leq \gamma \leq 1\}$ ) imposes the condition $\beta \in[0,1]$. In (5), the indicator function $I_{C^{-}}(\dot{\beta})$ (where $\left.C^{-}=\{\gamma / \gamma \leq 0\}\right)$ imposes that $\dot{\beta} \leq 0:$ the adhesion can only decrease and cannot be regenerated (it is not reversible) in the present model.

$$
\begin{aligned}
& \Psi\left(u_{\mathrm{N}}, u_{\mathrm{T}}, \beta\right)=1 / 2 \beta^{2} C_{\mathrm{N}} u_{\mathrm{N}}^{2}+1 / 2 \beta^{2} C_{\mathrm{T}}\left\|u_{\mathrm{T}}\right\|^{2}-w \beta+I_{\widetilde{K}}\left(u_{\mathrm{N}}\right)+I_{P}(\beta) \\
& \Phi\left(\dot{u}_{\mathrm{T}}, \dot{\beta}\right)=\mu(1-\beta)\left|R_{\mathrm{N}}-\beta^{2} C_{\mathrm{N}} u_{\mathrm{N}}\right|\left\|\dot{u}_{\mathrm{T}}\right\|+b /(p+1)|\dot{\beta}|^{p+1}+I_{C^{-}}(\dot{\beta})
\end{aligned}
$$




\section{The quasi-static problem}

The quasi-static formulation associated with the model including interface viscosity can be set as two variational inequalities (one of which is implicit) and a differential equation (extension of the formulation given in Cocou et al. (1996) and Raous et al. (1999)).

Problem $\left(P_{1}\right):$ Find $(\widetilde{u}, \beta) \in W^{1,2}(0, T ; V) \times W^{1,2}(0, T ; H)$ such that $\widetilde{u}(0)=\widetilde{u}_{0} \in K, \beta(0)=\beta_{0} \in H \cap[0,1[$ and for $\forall t \in[0, T], \widetilde{u}(t) \in K$, and

$$
\begin{array}{r}
a(\tilde{u}, v-\dot{\tilde{u}})+j\left(\beta, u_{\mathrm{N}}, v_{\mathrm{T}}\right)-j\left(\beta, u_{\mathrm{N}}, \dot{u}_{\mathrm{T}}\right)+ \\
\int_{\Gamma_{C}} \beta^{2} C_{\mathrm{T}} u_{\mathrm{T}} \cdot\left(v_{\mathrm{T}}-\dot{u}_{\mathrm{T}}\right) d s \geq(\tilde{F}, v-\dot{\tilde{u}})-\left\langle R_{\mathrm{N}}, v_{\mathrm{N}}-\dot{u}_{\mathrm{N}}\right\rangle \quad \forall v \in V, \\
-\left\langle R_{\mathrm{N}}, z-u_{\mathrm{N}}\right\rangle+\int_{\Gamma_{C}} \beta^{2} C_{\mathrm{N}} u_{\mathrm{N}} \cdot\left(z-u_{\mathrm{N}}\right) d s \geq 0 \quad \forall z \in K, \\
\dot{\beta}=-1 / b\left[w-\left(C_{\mathrm{N}} u_{\mathrm{N}}^{2}+C_{\mathrm{T}}\left\|u_{\mathrm{T}}\right\|^{2}\right) \beta\right]^{-} \quad \text { a.e. on } \Gamma_{C},
\end{array}
$$

where :

- $\tilde{u}=\left(u^{1}, u^{2}\right)$ where $u^{1}$ and $u^{2}$ define the displacements in $\Omega^{1}$ and $\Omega^{2}$,

- $V=\left(V^{1}, V^{2}\right), V^{\alpha}=\left\{v^{\alpha} \in\left[H^{1}\left(\Omega^{\alpha}\right)\right]^{3} ; v^{\alpha}=0\right.$ a.e. on $\left.\Gamma_{U}^{\alpha}\right\}, \alpha=1,2$ $\left(\Gamma_{U}^{\alpha}\right.$ are the parts of the boundaries where the displacements are prescribed),

- $H=L^{\infty}\left(\Gamma_{c}\right)$,

- $K=\left\{v=\left(v^{1}, v^{2}\right) \in V^{1} \times V^{2} ; v_{\mathrm{N}} \geq 0\right.$ a.e. on $\left.\Gamma_{c}\right\}$, where $\Gamma_{c}$ is the contact boundary between the two solids $\Omega_{1}$ and $\Omega_{2}$,

$-a(.,$.$) is the bilinear form classically associated to the elasticity map-$ ping,

- $j\left(\beta, u_{\mathrm{N}}, v_{\mathrm{T}}\right)=\int_{\Gamma_{C}} \mu(1-\beta)\left|\sigma\left(R_{\mathrm{N}}\right)-\beta^{2} C_{\mathrm{N}} u_{\mathrm{N}}\right|\left\|v_{\mathrm{T}}\right\| d s$, where $\sigma\left(R_{\mathrm{N}}\right)$ is a linear and compact mapping, $\sigma():. H^{-1 / 2}\left(\Gamma_{c}\right) \rightarrow L^{2}\left(\Gamma_{c}\right)$ (non local friction),

- $\widetilde{F}=\left(F^{1}, F^{2}\right)$ are the given force densities applied respectively to solid 1 and to solid 2 .

In Raous et al. (1999), an incremental formulation was given and the problem was solved by associating minimization techniques and a fixed point method on the sliding threshold for the contact, and a $\theta$-method for the differential equation. Details on the computational methods are presented extensively in Raous (1999). This quasi-static formulation was used to simulate the micro-indentation of a fiber in a $\mathrm{SiC} / \mathrm{SiC}$ composite and identify the constitutive parameters of the fiber-matrix interface. This formulation has been extended to hyper-elastic bodies in Bretelle et al. (2001). 


\section{The model with no viscosity : dynamic formulation}

In some cases, there is no mechanical reason to introduce a viscous dissipation in the interface behaviour. This is the case when this model is used to describe the propagation of a crack in a brittle bulk material, as we will now do. In order to study the influence of the characteristics of the fiber-matrix interface on the propagation of a crack in a composite material, we will suppose that the plane of propagation of the crack is given (which is of course a restrictive assumption) and we will use the adhesive model (without friction and without viscosity) on that plane considered as an interface (matrix-matrix and fiber-fiber "interfaces" because the crack propagates in both materials).

\subsection{The adhesion model with no viscosity}

The quasi-static problem for an adhesive contact without friction, considering a rate-independent cohesive model (no viscosity), can be written as presented in Problem $\left(P_{2}\right)$.

Problem $\left(P_{2}\right):$ Find $\widetilde{u} \in K$ such that :

$$
\begin{gathered}
a(\tilde{u}, v-\widetilde{u})-(\widetilde{F}, v-\widetilde{u})+\int_{\Gamma_{c}} R([\widetilde{u}], \beta) \cdot([v]-[\widetilde{u}]) \mathrm{ds} \geq 0 \quad \forall v \in K,(8) \\
\beta=h([\widetilde{u}]) \text { a.e. on } \Gamma_{c}
\end{gathered}
$$

where :

- $[\widetilde{u}]$ is the relative displacement on $\Gamma_{c},[\widetilde{u}]=u_{\mathrm{N}} n+u_{\mathrm{T}}$

- the contact force $R([\tilde{u}], \beta)$ is given by :

$$
R([\widetilde{u}], \beta)=\beta^{2}\left(C_{\mathrm{N}} u_{\mathrm{N}} n+C_{\mathrm{T}} u_{\mathrm{r}}\right)
$$

- $h([\widetilde{u}])$ is a given function deduced from (3) and satisfying the conditions $1 \geq \beta \geq 0$ and $\dot{\beta} \leq 0$; with an incremental formulation associated to Problem $\left(P_{2}\right), \beta^{\overline{k+1}}$ will be defined, at each time step $t^{k+1}$, by $\beta^{k+1}=\operatorname{Min}\left[1, \beta^{k}, w /\left(C_{\mathrm{N}}\left(u_{\mathrm{N}}{ }^{k+1}\right)^{2}+C_{\mathrm{T}}\left(\left\|u_{\mathrm{T}}\right\|^{k+1}\right)^{2}\right)\right]$.

In Cocou et al. (1997) and Raous et al. (1999), we gave a condition for the existence of a solution of the incremental form associated to Problem $\left(P_{1}\right)$ when a non local friction is considered. In Cocou and Rocca (2000), a similar condition was obtained on the quasi-static Problem $\left(P_{1}\right)$ itself (considering local friction). Here, for the frictionless problem with no viscosity for the adhesion evolution, existence is obtained and a condition ensuring uniqueness is established (Monerie (2000)). 


\section{Theorem}

There exists a fixed point, $\bar{k}$, for the application $s$ :

$s: k \rightarrow \eta([\widetilde{u}(k)])=R([\tilde{u}(k)], h([\tilde{u}(k)]))$

where $\tilde{u}$ is the solution of :

$$
a(\tilde{u}, v-\tilde{u})-(\tilde{F}, v-\tilde{u})+\int_{\Gamma_{c}} k \cdot([v]-[\tilde{u}]) \mathrm{ds} \geq 0 \quad \forall \mathrm{v} \in \mathrm{K} .
$$

and

$$
\left\|s\left(k_{1}\right)-s\left(k_{2}\right)\right\|_{L^{2}\left(\Gamma_{c}\right)} \leq \lambda l / c_{0}\left\|k_{1}-k_{2}\right\|_{L^{2}\left(\Gamma_{c}\right)}
$$

where :

- $c_{0}$ is the Lipschitz constant for the application

$R(.,):. L^{2}\left(\Gamma_{c}\right)^{3} \longrightarrow L^{2}\left(\Gamma_{c}\right)^{3}$,

$-l$ is the constant of coercivity of $a(.,$.$) ,$

- $\lambda$ is a constant related to the continuity of the injection from $H^{1 / 2}\left(\Gamma_{c}\right)^{3}$ to $L^{2}\left(\Gamma_{c}\right)^{3}$ and to the one of the trace mapping from $H^{1}\left(\Omega^{\alpha}\right)^{3}$ to $H^{1 / 2}\left(\Gamma_{c}\right)^{3}$ where $\alpha=1,2$.

The uniqueness condition $\left(\lambda l / c_{0} \leq 1\right)$ depends on the characteristics of the interface and on the elastic properties of the materials. An analysis of this condition on a simplified problem is given in Monerie (2000).

Because of the softening character of the interface law, the quasi-static problem is ill-posed, and rapid changes in the evolution of the solution may occur. A dynamic formulation of the problem is needed.

\subsection{The 3D dynamic formulation}

In order to deal with the non-viscous model used to describe the fracture propagation, a dynamic formulation is developed on the basis on the Non Smooth Contact Dynamics method given by Jean (1999) and Moreau $(1988,1999)$ for granular media. To treat correctly the nonsmooth character of the contact law, the dynamic problem is written in terms of differential measures and adapted to the adhesive and frictional law.

For the contact of a single solid with a rigid obstacle ( $q$ is the displacement and $r$ the contact force), the equation of motion

$$
M(q, t) \ddot{q}=F(q, \dot{q}, t)-r,
$$

is then written as :

$$
M(q, t) d \dot{q}=F(q, \dot{q}, t) d t-r d \nu,
$$

where $d \dot{q}$ is a differential measure associated to $\dot{q}(t)$ :

$$
\int_{t_{1}}^{t_{2}} d \dot{q}=q\left(t_{2}^{+}\right)-q\left(t_{1}^{-}\right) \forall t_{2}>t_{1},
$$


and then :

$$
\begin{aligned}
\int_{t_{1}}^{t_{2}} M(q, t) d \dot{q} & =\int_{t_{1}}^{t_{2}} F(q, \dot{q}, t) d t-\int_{] t_{1}, t_{2}\right]} r d \nu \\
q\left(t_{2}\right) & =q\left(t_{1}\right)+\int_{t_{1}}^{t_{2}} \dot{q}(\tau) d \tau
\end{aligned}
$$

The formulation due to Jean $(1999)$ and Moreau $(1988,1999)$ is extended here to the adhesive frictional model (Monerie (2000)). The non linear problem is then solved by using a generalization of a NewtonRaphson algorithm to non-smooth functions due to Alart and Curnier (1991). The implementation is performed in the 3D finite element code LMGC (see Jean (1999) and Monerie and Acary (2001)).

\section{Fracture of composite material}

\subsection{The problem}

When a crack propagates in a composite material, various mechanisms can occur depending on the characteristics of the interface : crack trapping, crack bridging or fiber breaking as shown in Figure 4. Various contributions can be found in He et al. (1989), Leguillon et al. (2000), Mathur et al. (1996), Needlemann and Tvergaard (1998), Tvergaard (1990), Siegmund et al. (1997), and Xu et al. (1997, 1998).
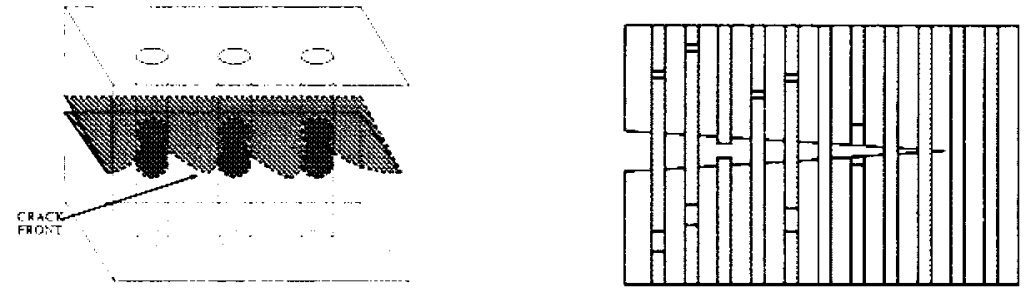

Figure 4. Crack trapping, crack bridging and fiber breaking.

The following simulations show the influence of the interface characteristics on the crack propagation.

As presented in Figure 5, a cell composed of a single fiber surrounded by a matrix domain is considered. The boundary conditions are chosen in order to respect the symmetry and to approximate a semi-infinite domain. An increasing displacement is prescribed on the top of the cell and the crack is assumed to propagate along the symmetry plane at the bottom, both in the matrix and in the fiber. 


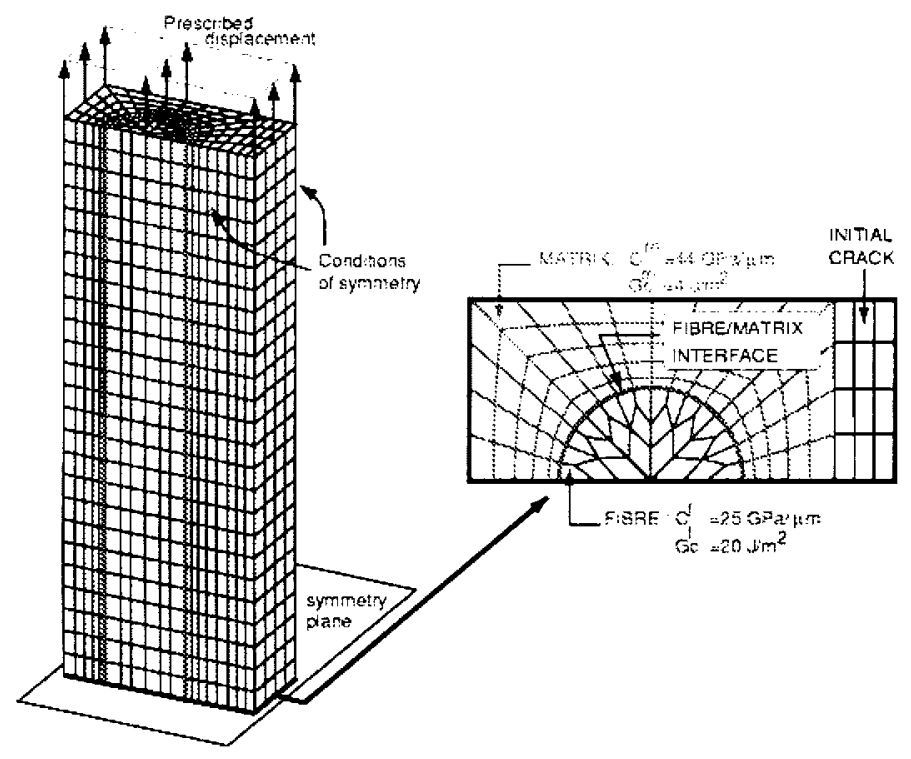

Figure 5. Mesh of the fiber and the surrounding matrix (12246 ddl).

\subsection{Identification of the parameters}

The interface model with no friction and no viscosity is used to simulate the crack propagation in the matrix and in the fiber (matrix-matrix and fiber-fiber "interfaces"). The parameters $C_{\mathrm{N}}^{m}$ and $C_{\mathrm{N}}^{f}\left(C_{\mathrm{T}}=0\right.$ because of the symmetry of the problem) and $w^{m}$ and $w^{f}$ for both materials (subscripts $m$ and $f$ relate respectively to the matrix and to the fiber) are evaluated by considering :

- the stiffnesses of the materials (the Young moduli are $E^{m}=350 G P a$ for the matrix, and $E^{f}=200 G P a$ for the fiber) and the maximum deformation before collapse, to identify the contact stiffnesses $C_{\mathrm{N}}^{m}$ and $C_{\mathrm{N}}^{f}$ $\left(C_{\mathrm{N}}^{m}=0.044 N / \mu m^{3}, C_{\mathrm{N}}^{f}=0.025 N / \mu m^{3}\right)$,

- the decohesive energy and the restitution energy, to identify the thresholds $w^{m}$ and $w^{f}\left(w^{m}=4 J / m^{2}, w^{f}=20 J / m^{2}\right)$.

We introduce $\bar{\sigma}$, which is the maximum stress supported by the interfaces, defined by $\bar{\sigma}=\sqrt{C_{\mathrm{N}} w}$. Thus, we have $: \bar{\sigma}^{f}=707 M P a$ and $\bar{\sigma}^{m}=418 M P a$.

To simulate the fiber-matrix interface, the results presented here were based on the same model, with no interface viscosity and no friction. As shear is dominant for the present loading, the maximum stress $\bar{\sigma}^{i}$ for the fiber-matrix interface depends mainly on the sliding effect and therefore $\bar{\sigma}^{i}=\sqrt{C_{\mathrm{T}}^{i} w^{i}}$. Various values of $\bar{\sigma}^{i}$ have been tested in the numerical 
simulations in order to determine the influence of this parameter on the crack propagation process.

\subsection{The crack propagation}

In Figures 6 and 7, the propagation of the crack is presented for two kinds of interfaces :

- a strong interface in Figure 6 where $\bar{\sigma}^{i}=247 M P a$,

- a weak interface in Figure 7 where $\bar{\sigma}^{i}=3.5 M P a$.

Figure 6 and 7 give the evolution of the reaction force on the top of the cell when the prescribed displacement increases. The inserted pictures show the solutions at different steps of the loading. The dark zones correspond to the parts where there is no more adhesion, i.e. where the crack is open or where the fiber slides along the matrix.

In Figure 6 (strong interface), it can be noted that the composite behaves like a single material with variable characteristics (corresponding to those of the matrix and of the fiber) and it turns out to be rather brittle : both the matrix and the fiber are broken when the prescribed displacement is about $0.1 \mu \mathrm{m}$.

Figure 7 shows that a weak interface protects the fiber from breaking for a larger loading : part of the energy is dissipated into the fibermatrix interface and the total collapse of the cell occurs only when the prescribed displacement is about $0.4 \mu m$ (i.e., when it is four times larger than in the previous case).

In this work, the RCC model is extended for modeling crack propagation in composite materials. A dynamic formulation is used because viscosity is not considered for the evolution of the adhesion intensity. The 3D simulations of the propagation of a crack taking into account the debonding on the fiber-matrix interfaces shows the dependence of the process on the properties of these interfaces. The results should help to improve the toughness of fiber-reinforced composites by choosing appropriate characteristics of these interfaces. 


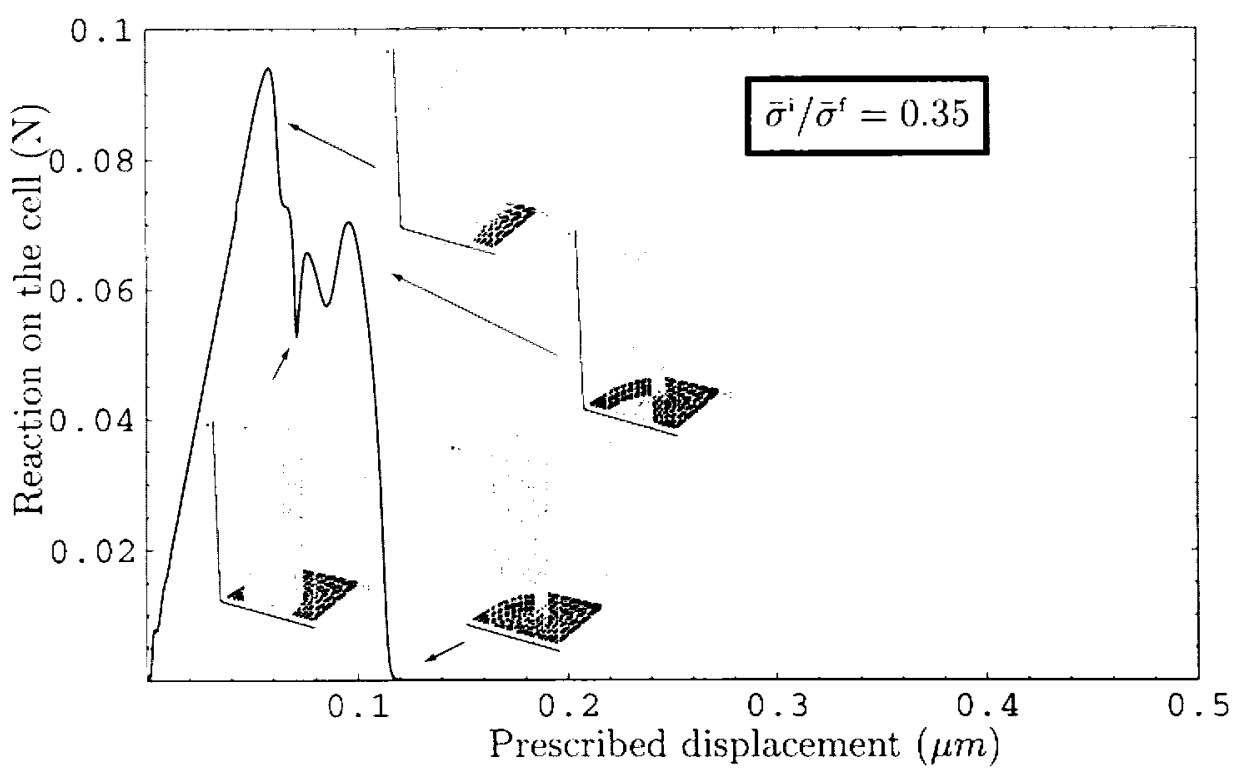

Figure 6. Propagation of the crack and of the breakdown area of the interface (strong interface).

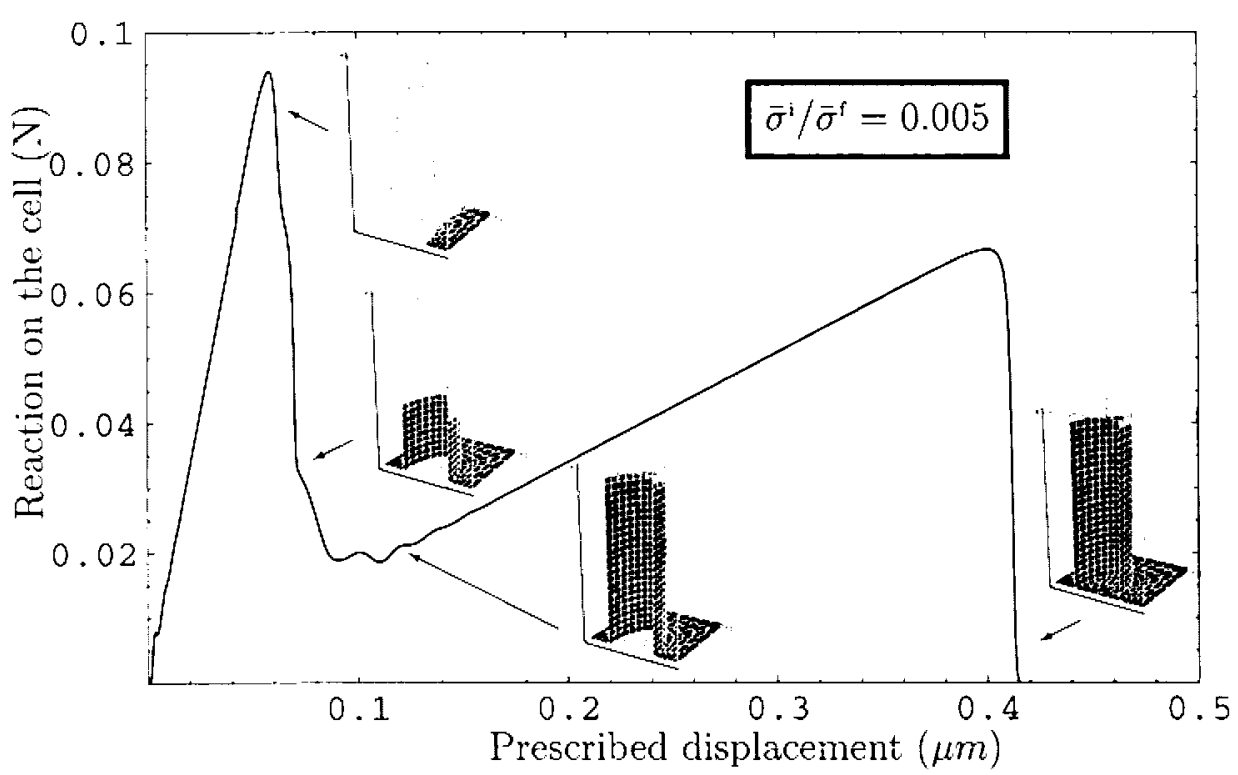

Figure 7. Propagation of the crack and of the breakdown area of the interface (weak interface). 


\section{References}

Alart, P., and Curnier, A. (1991) A generalised Newton method for contact problems with friction, J. Mech. Théor. Appliq. 7, 67 - 82.

Allix, O., Ladevèze, P., and Corigliano, A. (1995) Damage analysis of interlaminar fracture specimen, Composite Structures 31(1), 61 - 74.

Allix, O., Lévèque, D., and Perret, L. (1998) Identification and forecast of delamination in composite laminates by an interlaminar interface model, Composites Science and Technologie, 58, $671-678$.

Bretelle, A.-S., Cocou, M., and Monerie, Y. (2001) Unilateral contact with adhesion and friction between two hyperelastic bodies, Int. J. Engrg. Sci. 39, 2015 - 2032.

Cangémi, L. (1997) Frottement et adhérence : modèle, traitement numérique et application à l'interface fibre/matrice, Thesis, Université de la Méditerranée, Marseille.

Chaboche, J.-L., Girard, R., and Levasseur, P. (1997) On the interface debonding model, Int. J. Damage Mechanics 6, 220 - 257.

Chaboche, J.-L., Feyel, F., and Monerie, Y. (2001) Interface debonding model : a viscous regularization with a limited rate dependency, Int. J. Solids Structures 38(18), 3127 - 3160 .

Cocou, M., Pratt, E., and Raous, M. (1996) Formulation and approximation of quasistatic frictional contact, Int. J. Eng. Sci. 34(7), 783 - 798.

Cocou, M., Cangémi, L., and Raous, M. (1997) Approximation results for a class of quasistatic contact problem including adhesion and friction, in Variation of domains and free-boundary problems in solids mechanics, edited by A. Argoul, M. Frémond and Q.S. Nguyen, Solid Mechanics and its Applications 66, Kluwer, $211-218$.

Cocou, M., and Rocca, R. (2000) Existence results for unilateral quasistatic contact problems with friction and adhesion, Math. Model. Num. Anal. 34(5), 981-1001.

Frémond, M. (1987) Adhérence des solides, J. Méc. Thé. Appl. 6(3), 383 - 407.

Frémond, M. (1988) Contact with adhesion, in Nonsmooth Mechanics and Applications, edited by J.J. Moreau and P.D. Panagiotopoulos, CISM - Courses and Lectures 302, Springer Verlag, $177-221$.

He, M.Y., and Hutchinson, J.W. (1989) Crack deflection at an interface between dissimilar elastic materials, Int. J. Solids Structures 25, 1053 - 1067.

Jean, M. (1999) The Non Smooth Contact Dynamics method, Computer Meth. Appl. Mech. and Engrg. 177(3-4), 235 - 257.

Ladevéze, P. (1995), A damage computational approach for composites : basic aspects and mircomechanical relations, Computational Mechanics 17, 142 -150.

Leguillon, D., Lacroix, C., and Martine, E. (2000) Interface debonding ahead of a primary crack, J. Mech. Phys. of Solids 48, 2137-2161.

Mathur, K.K., Needleman, A., and Tvergaard, V. (1996) Three dimensional analysis of dynamic ductile crack growth in a thin plate, J. Mech. Phys. Solids 44(3), 439 -464 .

Michel, J.-C., and Suquet, P. (1994) An analytical and numerical study of the overall behaviour of metal-matrix composites, Model. Simul. Mater. Sci. 2, 637 - 658.

Michel, J.-C., Suquet, P., and Thébaud, F. (1994) Une modélisation du rôle des interfaces dans le comportement des composites à matrice métallique, Rev. Eur. Elém. Finis 3(4), 573 - 595.

Monerie, Y. (2000) Fissuration des matériaux composites : rôle de l'interface fibrematrice, Thesis, Université de la Méditerranée, Marseille. 
Monerie, Y., Raous, M., Leroy, F.-H., Sudre, O., Feyel, F., and Chaboche, J.-L. (1998) Comparaison de lois d'interface fibre/matrice sur la base d'un modèle uni-axial d'expérience de micro-indentation, in Comptes Rendus des Onzièmes Jounées $\mathrm{Na}$ tionales sur les Composites, edited by J. Lamon and D. Baptiste, AMAC publisher, $565-574$.

Monerie, Y., and Raous, M. (2000) A model coupling adhesion to friction for the interaction between a crack and a fibre-matrix interface, Zeitschrift für Angewandte Mathematik und Mechanik 80, 205 - 209.

Monerie, Y., and Acary, V. (2001) Formulation dynamique d'un modèle de zone cohésive tridimensionnel couplant endommagement et frottement, Rev. Eur. Elém. Finis 10, 489 - 504.

Moreau, J.-J. (1988) Unilateral contact and dry friction in finite freedom dynamics, in Non Smooth Mechanics and Applications, edited by J.J. Moreau and P.D. Panagiotopoulos, CISM Courses and lectures 302, 1 - 82.

Moreau, J.-J. (1999) Some basics of unilateral dynamics, in Unilateral Multibody Contacts, edited by F. Pfeiffer and Ph. Glocker, Solid Mechanics and its applications 72 , Kluwer, 1 - 14 .

Needleman, A. (1990) An analysis of tensile decohesion along an interface, J. Mech. Phys. Solids 38(3), 289-324.

Needleman, A., and Tvergaard, V. (1998) Dynamic crack growth in a nonlocal progressively cavitating solid, Eur. J. Mech. A/Solids 17(3), $421-438$.

Raous, M. (1999) Quasistatic Signorini problem with Coulomb friction and coupling to adhesion, in New developments in contact problems, edited by P.WriggersP.Panagiotopoulos, CISM Courses and Lectures 384, Springer Verlag, 101 - 178.

Raous, M., Cangémi, L., and Cocou, M. (1999) Consistent model coupling adhesion, friction and unilateral contact, Comp. Meth. in Appl. Mech. and Engrg. 177(3-4), 383 - 399.

Raous, M., Cangémi, L., and Cocou, M. (1997) Un modèle couplant adhérence et frottement pour le contact unilatéral entre deux solides déformables, $C$. $R$. Acad. Sci. Paris, Série II b 329, 503 - 509.

Siegmund, T., Fleckand, N.A., and Needleman, A. (1997) Dynamic crack growth across an interface, Int. $J$. of Fracture 85, $381-402$.

Truong Dinh Tien, J.-M. (1990) Contact avec adhérence, Thesis, Université de Paris VI, Paris.

Tvergaard, V. (1990) Effect of fibre debonding in a whisker-reinforced metal, Mat. Sci. Engrg. A125, 203 - 213.

Tvergaard, V., and Needleman, A. (1995) Effects of nonlocal damage in porous plastic solids, Int. J. Solids Structures 32, 1063 - 1077.

Tvergaard, V., and Needleman, A. (1997) Nonlocal effects on localization in a voidsheet, Int. J. Solids Structures 34(18), 2221 - 2238.

Vola, D., Pratt, E., Jean, M., and Raous, M. (1998) Consistent time discretization for dynamical frictional contact problems and complementarity techniques, Rev. Eur. Eléments Finis 7, 149 - 162.

Xu, X.-P., Needleman, A., and Abraham, F.F. (1997) Effect of inhomogeneities on dynamic crack growth in an elastic solid, Model. Simul. Mater. Sci. Engrg. 5, 489 - 516.

$\mathrm{Xu}$, G., Bower, A.F., and Ortiz, M. (1998) The influence of crach trapping on the toughness of fiber-reinforced composites, J. Mech. Phys. Solids 46(10), 1815 1833. 